\title{
A Rapid Low Power Ultra-Violet Light-Assisted Bacterial Sensor for Coliform Determination
}

\author{
Jia Shin Ho, Chee-Seng Toh* \\ Division of Chemistry and Biological Chemistry, School of Physical and Mathematical Sciences, Nanyang Technological \\ University, Singapore \\ Email: *cstoh@ntu.edu.sg
}

Received May 29, 2013; revised June 30, 2013; accepted July 2, 2013

Copyright (C) 2013 Jia Shin Ho, Chee-Seng Toh. This is an open access article distributed under the Creative Commons Attribution License, which permits unrestricted use, distribution, and reproduction in any medium, provided the original work is properly cited.

\begin{abstract}
Titanium dioxide $\left(\mathrm{TiO}_{2}\right)$ particle-incorporated Prussian blue (PB) sensor for the detection and inactivation of Escherichia coli (E. coli) is developed in this study. The system requires low power ultra-violet (UV) light to photoactivate $\mathrm{TiO}_{2}$ particles and change of signal response is measured immediately upon irradiation using cyclic voltammetry. The generation of free radical species $(\mathrm{OH} \cdot)$ and $\mathrm{H}_{2} \mathrm{O}_{2}$ from the oxidation of water by the hole $\left(h^{+}\right)$are the main components which cause destruction of cell membrane and eventually result in the inactivation of cell. Our study also shows direct oxidation of cells by $h^{+}$as one of the mechanisms for cell inactivation due to the close contact between $\mathrm{TiO}_{2}$ particles and E. coli cells. Highly attractive features of this unique sensor include its ability to be regenerated and reused for at least three times without the use of harsh chemicals, good reproducibility and its specificity in bacteria sensing when tested against organic contaminants, which potentially reduce the operation cost when incorporated into water disinfection system. Its superior performance in detection of total coliform without additional steps of sample treatment is also demonstrated in river water. $\mathrm{TiO}_{2}$ particle-incorporated $\mathrm{PB}$ membrane sensor exhibits signal response with higher current output compared to $\mathrm{PB}-\mathrm{TiO}_{2}$ coated screen printed carbon electrode (SPCE) due to its porous structure and higher surface area, suggesting its potential development into a powerful and low cost contamination monitoring tool.
\end{abstract}

Keywords: Bacterial Sensor; Low Power; Cell Inactivation; E. coli; Coliform; Photocatalysis

\section{Introduction}

Water contamination is one of the most problematic issues where millions of people die from water borne diseases due to the consumption of unsafe or contaminated water. Escherichia coli $(E$. coli) has been identified as one of the agents for waterborne diseases and its presence in water represents water quality deterioration and contamination by human or animal wastes [1]. This poses serious health risks, such as diarrhea, nausea and other symptoms to consumers, especially infants and those with severely compromised immune system. The contamination of water source by bacteria and pathogen also leads to limited sustainable water supply where one-fifth of world's population has no clean access to water and this scenario is more prominent in developing countries [2]. Hence, there is an urgent need to develop rapid, low cost and simple bacterial sensor with early warning capability and of low power $[3,4]$ in order to address these problems. Electrochemical sensing which is portable and

"Corresponding author. inexpensive has shown its superior performances in the detection of cells, viruses and biological samples [5-8]. However, real-time detection and regeneration of sensing materials have always been the limitations for biosensing [9]. An electrochemical sensor which exhibits immediate response upon detection and the ability to be reused is expected to be highly useful due to the potential enhanced performance for on-site analysis.

$\mathrm{TiO}_{2}$ photocatalyst has been used extensively for the photocatalytic degradation of organic compounds for water purification $[10,11]$. However, the development of photocatalytic reactors remains a challenge due to the high recombination rates of holes and electrons [12] and the lack of ability to regenerate and reuse the material. On the contrary, a polymer incorporated with $\mathrm{TiO}_{2}$ would be expected to partly resolve the problem of recombination because the polymer serves as the electron acceptor in the conduction band. To develop a low power bacterial sensor, we choose iron hexacyanoferrate polymer which is also known as Prussian blue (PB), incorporated with titanium dioxide $\left(\mathrm{TiO}_{2}\right)$ particles as the sensing material. 
Two electrode configurations, namely porous alumina membrane and screen printed carbon electrode (SPCE) have been employed in this study to investigate the performance of sensor. The polymer incorporated $\mathrm{TiO}_{2}$ is deposited onto the platinum-coated porous alumina membrane template and SPCE, which act as the working electrode in this study. The setup of polymer-coated membrane sensor operates like a conventional two-electrode electrochemical system but requires only a very low power ultra-violet (UV) lamp to function while SPCE functions as a conventional three-electrode system.

Ultrathin PB film is employed in this work because it can significantly improve the signal response and improve the sensitivity owing to the fast mass transfer of analytes $[13,14]$. In this study, the sensing of bacteria is carried out without the labeling of antibody as well as with small volume which significantly simplifies the procedures for operation. To further enhance the sensing performance of sensor, large $\mathrm{TiO}_{2}$ particle size is chosen owing to its good mechanical adhesion [15] and to maximize interaction between particles and bacteria. The two-electrode system used in this work is simple and potentially useful in the application of field measurement conditions. Herein, we utilize a $\mathrm{TiO}_{2}$ particles incorporated PB film to construct a novel membrane sensor with bacterial sensing capability in small volume of analytes with the aid of low power UV light (Scheme 1). E. coli sensing and detection of total coliform in river water are performed by the sensor using cyclic voltammetry. To further evaluate the application of $\mathrm{TiO}_{2}$ incorporated $\mathrm{PB}$ sensor on E. coli detection, the performance of SPCE coated with $\mathrm{PB}$ and $\mathrm{TiO}_{2}$ is also investigated in this study.

\section{Experimental}

\subsection{Materials and Instruments}

Nanoporous alumina membrane (Anodisc ${ }^{\mathrm{TM}}, 13 \mathrm{~mm}$ diameter, $0.02 \mu \mathrm{m}$ pore size) was purchased from Whatman (Maidstone, Kent, UK). SPCE was obtained from

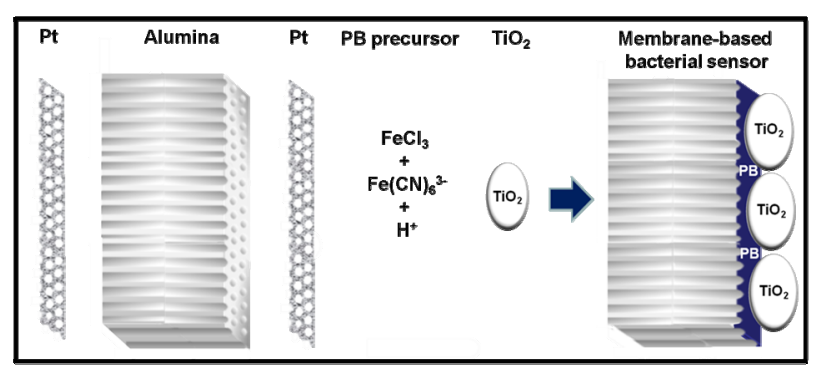

Scheme 1. Fabrication of the membrane-based bacterial sensor by sputtering $\sim 50 \mathrm{~nm}$ thick platinum layer on both sides of $60 \mu \mathrm{m}$ thick nanoporous alumina membrane, followed by coating of $\mathrm{TiO}_{2}$ incorporated $\mathrm{PB}$ film galvanostatically onto the Pt electrode.
Dropsens. The working electrode (4 $\mathrm{mm}$ diameter) of SPCE was carbon $(\mathrm{C})$ while the counter and reference electrodes were platinum $(\mathrm{Pt})$ and silver $(\mathrm{Ag})$ respectively. Hydrochloric acid $(\mathrm{HCl}, 37 \%)$ was obtained from P. P. Chemical. Potassium chloride $(\mathrm{KCl})$ was purchased from Sinopharm Chemical Reagent Co. Ltd. Potassium hexacyanoferrate (III) $\left(\mathrm{K}_{3} \mathrm{Fe}(\mathrm{CN})_{6}\right)$ and Nafion perfluorinated ion-exchange resin were obtained from SigmaAldrich. Anhydrous iron (III) chloride $\left(\mathrm{FeCl}_{3}\right)$ was purchased from Merck. Titanium (IV) oxide $\left(\mathrm{TiO}_{2},-325\right.$ mesh powder, anatase, 99.6\%) was obtained from Alfa Aesar. Methanol $(\mathrm{MeOH}, \geq 99.9 \%)$ was purchased from Tedia Company, Inc., toluene $\left(\mathrm{C}_{6} \mathrm{H}_{5} \mathrm{OH}, 99.5 \%\right)$ was obtained from RCI Labscan Limited and 1,4-dioxane $\left(\mathrm{C}_{4} \mathrm{H}_{8} \mathrm{O}_{2}, \geq 99.9 \%\right)$ was purchased from Merck. E. coli $\mathrm{K} 12$ was obtained from ATCC and it was prepared in $0.01 \mathrm{M}$ phosphate buffered saline (PBS, $\mathrm{pH}$ 7.4). All chemicals and solvents were used as received. Ultrapure water (Sartorius Ultrapure Water System) was used for all solution preparation, unless otherwise stated.

Sputter coating of $\mathrm{Pt}$ onto the nanoporous alumina membrane was performed by JEOL Auto Fine Coater (JFC-1600). Coating of $\mathrm{TiO}_{2}$ incorporated PB onto the electrodes and electrochemical measurements were carried out by e-corder $401(\mathrm{eDaQ})$ and potentiostat $(\mathrm{eDaQ}$ EA161) controlled by a PC.

\subsection{E. coli Culturing}

E. coli $\mathrm{K} 12$ was purchased from ATCC. Luria Broth (LB) containing $10.0 \mathrm{~g}$ tryptone, $5.0 \mathrm{~g}$ yeast extract and $10.0 \mathrm{~g}$ sodium chloride was used to grow the pure culture of $E$. coli. The culture was grown on an orbital shaker at $37^{\circ} \mathrm{C}$ for $18 \mathrm{~h}$ and it was subsequently diluted to $10 \mathrm{cfu} \cdot \mathrm{mL}^{-1}$ with $0.01 \mathrm{M}$ PBS, pH 7.4. E. coli cell number was enumerated by spread plate method where $0.1 \mathrm{~mL}$ of diluted solution was spread evenly on LB agar plate and incubated at $37^{\circ} \mathrm{C}$ for $24 \mathrm{~h}$. E. coli colonies on the plates were counted for determination of the number of viable cell in colony-forming units per milliliter $\left(\mathrm{cfu} \cdot \mathrm{mL}^{-1}\right)$.

\subsection{River Water Spiking}

One-liter of water sample was collected from Kallang river, Singapore on 16 Jan 2013. The water sample was divided into three equal volumes and two of the solutions were spiked with different volumes of $30 \mathrm{cfu} \cdot \mathrm{mL}^{-1} E$. coli solution to make up the desired spiked concentration. All solutions were finally made up to equal volumes using PBS. The electrochemical measurement was then carried out according to the procedures stated below.

\subsection{Sensor Fabrication}

Fabrication of $\mathrm{TiO}_{2}$ incorporated $\mathrm{PB}$ membrane sensor was based on the procedure described elsewhere [16]. 
Both sides of the nanoporous alumina membrane were sputtered with conductive Pt layers and it was subsequently electrodeposited with PB (Scheme 1). The active side of the sputtered membrane served as the working electrode while the passive side of the membrane as counter electrode and silver/silver chloride $(\mathrm{Ag} / \mathrm{AgCl})$ in $1 \mathrm{M} \mathrm{KCl}$ was used as the reference electrode during the coating process. The membrane was coated using galvanostat for $1 \mathrm{~h}$ in an aqueous solution of $20 \mathrm{mM}$ $\mathrm{K}_{3} \mathrm{Fe}(\mathrm{CN})_{6}$ and $20 \mathrm{mM} \mathrm{FeCl}_{3}$ with $\mathrm{pH}$ adjusted to be around 2.0 using $\mathrm{HCl}$. $\mathrm{TiO}_{2}$ particles were suspended in the same solution with a concentration of $15 \mathrm{~g} \cdot \mathrm{dm}^{-3}$. The solution was stirred and dropped onto the surface of membrane every 10 min to ensure that $\mathrm{TiO}_{2}$ was coated together with $\mathrm{PB}$. The current density was $20 \mu \mathrm{A} \cdot \mathrm{cm}^{-2}$ and total electrolysis charge passed was $72.2 \mathrm{mC} \cdot \mathrm{cm}^{-2}$. The $\mathrm{TiO}_{2}$ incorporated $\mathrm{PB}$ membrane was then rinsed with ultrapure water and dried overnight at room temperature. The passive side of the membrane was coated with Nafion before it was used for sensing. The coating of SPCE was accomplished by the same procedures except $\mathrm{Pt}$ and $\mathrm{Ag}$ were used as the counter and reference electrodes respectively.

\subsection{Sensing and Disinfection of E. coli}

E. coli sensing was carried out by spreading $20 \mu \mathrm{L}$ of $E$. coli solution on both sides of the membrane and the working electrode of SPCE prior to irradiation and signal response was obtained from cyclic voltammogram (CV). The sensor was then subjected to UV light irradiation which the source was a $4 \mathrm{~W}$ money detector (MD401, Khind) before the determination of electrochemical response. After the first measurement, the sensor was rinsed with copious amount of PBS to remove bacteria from the previous scan. Higher concentration of E. coli solution was applied onto the sensor and the signal response was determined again. The electrochemical measurement system comprised an integrated two-electrode setup or SPCE as well as e-corder 401 (eDaQ) and potentiostat (eDaQ EA161) controlled by a PC.

\section{Results and Discussion}

\subsection{Model for Bacterial Sensor Signal Response}

The $\mathrm{TiO}_{2}$ incorporated $\mathrm{PB}$ membrane sensor presents a large signal response toward E. coli solution upon irradiation in contrast to the signal response before exposure of light (Figure 1(a)). This remarkably high electroactivity of bacterial sensor cannot be observed on sensor in the absence of PB films (Figure 2(a)) because electron transfer is harder to occur in $\mathrm{TiO}_{2}$ due to its larger band gap of $3.2 \mathrm{eV}$ [17]. The change of peak current is insignificant when PB sensor without $\mathrm{TiO}_{2}$ is used (Figure 2(b)). This clearly indicates that bacteria sensing happens only when there are photogenerated electrons and highly reactive radical species from $\mathrm{TiO}_{2}$ particles. Further evaluation of the sensor in differentiating its signal response from organic compound, methanol reveals insignificant change of signal response (Figure 1(b)). The difference in electrochemical behaviors can be explained by the chemical reaction of $\mathrm{PB}$ and methanol [18] causing the PB film to dissolve away thereby, reducing electrochemical activity.

The significantly high oxidative current of bacterial sensor upon irradiation is owing to the formation of Prussian white (PW) as a result of injection of photoexcited electron into PB as shown in Scheme 2. A hole $\left(h^{+}\right)$ and electron $\left(e^{-}\right)$pair is generated in the valence and conduction bands respectively when $\mathrm{TiO}_{2}$ is illuminated with light of appropriate wavelength $(300-400 \mathrm{~nm})$. The valence band $h^{+}$reacts with water molecule to produce hydroxyl radical $(\mathrm{OH} \cdot)$ and the recombination of $\mathrm{OH}^{\cdot}$ produces hydrogen peroxide $\left(\mathrm{H}_{2} \mathrm{O}_{2}\right)$. To prevent the ex-

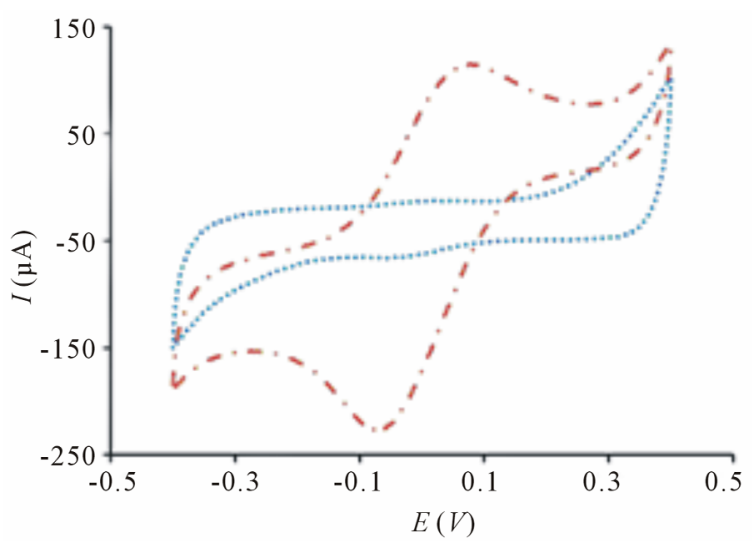

(a)

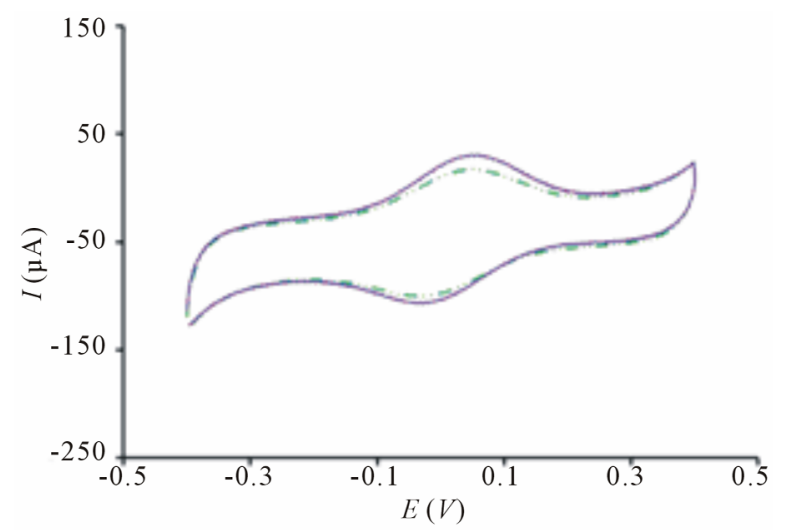

(b)

Figure 1. Cyclic voltammogram of $\mathrm{TiO}_{2}$ incorporated $\mathrm{PB}$ membrane sensor with (a) $20 \mu \mathrm{L} 10 \mathrm{cfu} \cdot \mathrm{mL}^{-1}$ of $E$. coli before ( ..........) and after (- - - ) UV light irradiation (b) $20 \mu \mathrm{L}$ of methanol before $(-\ldots)$ ) and after ( - ) UV light irradiation. Conditions: scan rate $=20 \mathrm{mV} \cdot \mathrm{s}^{-1}$, potential range $=-0.4$ to $0.4 \mathrm{~V}, E$. coli concentration $=10$ cfu $\cdot \mathrm{mL}^{-1}$, methanol concentration $=\mathbf{2 0} \%(\mathrm{v} / \mathrm{v})$. 


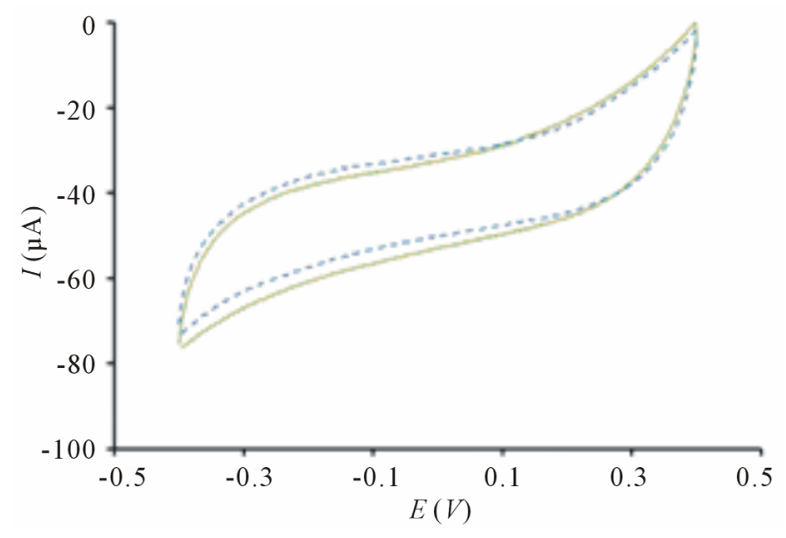

(a)

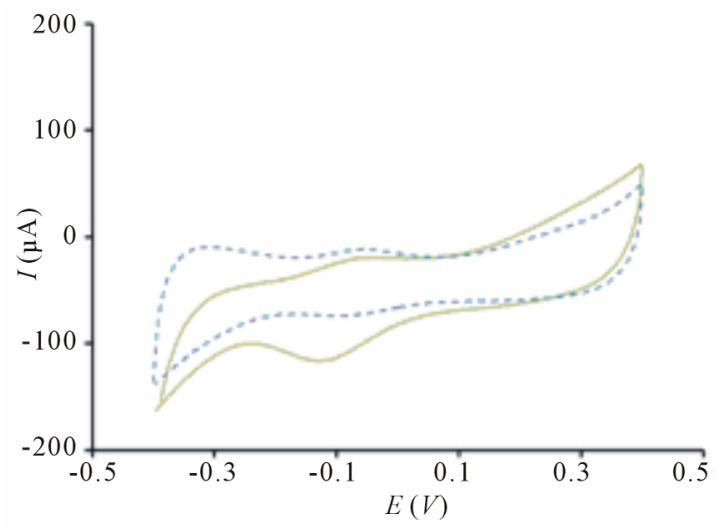

(b)

Figure 2. Cyclic voltammogram of (a) $\mathrm{TiO}_{2}$ sensor without PB before ( - ) and after (- -- ) irradiation; (b) PB sensor without $\mathrm{TiO}_{2}$ before ( - ) and after (- - ) irradiation. Conditions: scan rate $=20 \mathrm{mV} \cdot \mathrm{s}^{-1}$, potential range $=-0.4$ to $0.4 \mathrm{~V}, E$. coli concentration $=10 \mathrm{cfu} \cdot \mathrm{mL}^{-1}$.

tremely deleterious $e^{-}-h^{+}$recombination reaction, $\mathrm{PB}$ with compatible band gap energy [19] was chosen to $\mathrm{TiO}_{2}$ particles as the bacteria sensing material. In this study, the bacteria sensing is proposed to be coupled with disinfection of bacteria, where highly reactive $\mathrm{OH} \cdot$ and $\mathrm{H}_{2} \mathrm{O}_{2}$ are responsible for cell wall decomposition, subsequently change the cell membrane permeability [20-24]. Hence, the disinfection of $E$. coli is mainly due to the destruction of cell wall and followed by cell membrane which permeability change allows the penetration of highly reactive species into the cytoplasmic membrane. Direct oxidation of cells by $h^{+}$has also been proposed previously but the detailed mechanism has not been discussed extensively $[24,25]$.

\subsection{Analytical Performance of Bacterial Sensor}

Figure 3 illustrates the correlation between oxidative current with increasing concentration of $E$. coli upon irradiation. The bacterial sensor shows significant change of response upon irradiation and the short analysis time outperforms the conventional methods for detection of $E$. coli in water, including multiple-tube fermentation and membrane filter techniques which require time-consuming and labor-intensive procedures [26]. The correlation between logarithm concentration of $E$. coli and oxidative peak current is somewhat linear between 10 to $10^{5}$ $\mathrm{cfu} \cdot \mathrm{mL}^{-1}$ (Figure 3) and it can be established using the equation:

$$
\frac{I_{\mathrm{p}}-I_{\mathrm{p}, 0}}{k_{1}}=\log \frac{[c]}{k_{2}}
$$

where $I_{\mathrm{p}}$ and $I_{\mathrm{p}, 0}$ are the oxidative peak currents in the presence and absence of E. coli, $k_{1}$ and $k_{2}$ are constants and $[c]$ is the concentration of E. coli.

The calibration plot is obtained from three independent sets of experiments with three different sensors. The increase contact between $\mathrm{TiO}_{2}$ particles and higher concentration of $E$. coli explains the relationship of signal response and E. coli concentration [24]. The $h^{+}$generated can react with cells [25] more rapidly and it can also be filled more readily by electrons generated from the decomposition of cells which have close contact with $\mathrm{TiO}_{2}$ particles [24]. Whereas for lower concentration of cells, less cells can be oxidized by the $h^{+}$thus, resulting in lower oxidative current. This suggests direct oxidation of cells as one of the mechanisms occurring in our study of cell disinfection.

\subsection{Interference Study}

The effect of organic contaminants on the sensor is evaluated with three organic compounds, toluene, methanol and 1,4-dioxane which are commonly found in industrial effluent and ground water contaminated by point emissions [27-29]. All sensor signal responses are derived from the peak currents of the potential scans and offset against the potential scan obtained in the absence of $E$. coli cells. Figure 4 reveals the sensor signal response toward E. coli, mixture of E. coli with organic contaminants and $1 \mathrm{~h}$ after suspension of $E$. coli in the organic mixtures. The sensor was first applied with $10 \mathrm{cfu} \cdot \mathrm{mL}^{-1}$ E. coli solution to obtain the signal response. A mixture of three organic compounds, $0.05 \mathrm{ppm}$ 1,4-dioxane, $0.002 \mathrm{ppm}$ methanol and $0.002 \mathrm{ppm}$ toluene were then added into the E. coli solution and applied onto the sensor to obtain the second signal response. These concentrations were chosen because these are the possible levels of contaminants present in polluted water [27-29]. There is insignificant change of signal response even after the sensor was exposed to organic contaminants, demonstrating that the presence of organic contaminants does not passivate nor interfere with the sensor performance on bacteria sensing. After $1 \mathrm{~h}$ suspension of E. coli in organic mixtures, the solution was applied onto the sen- 


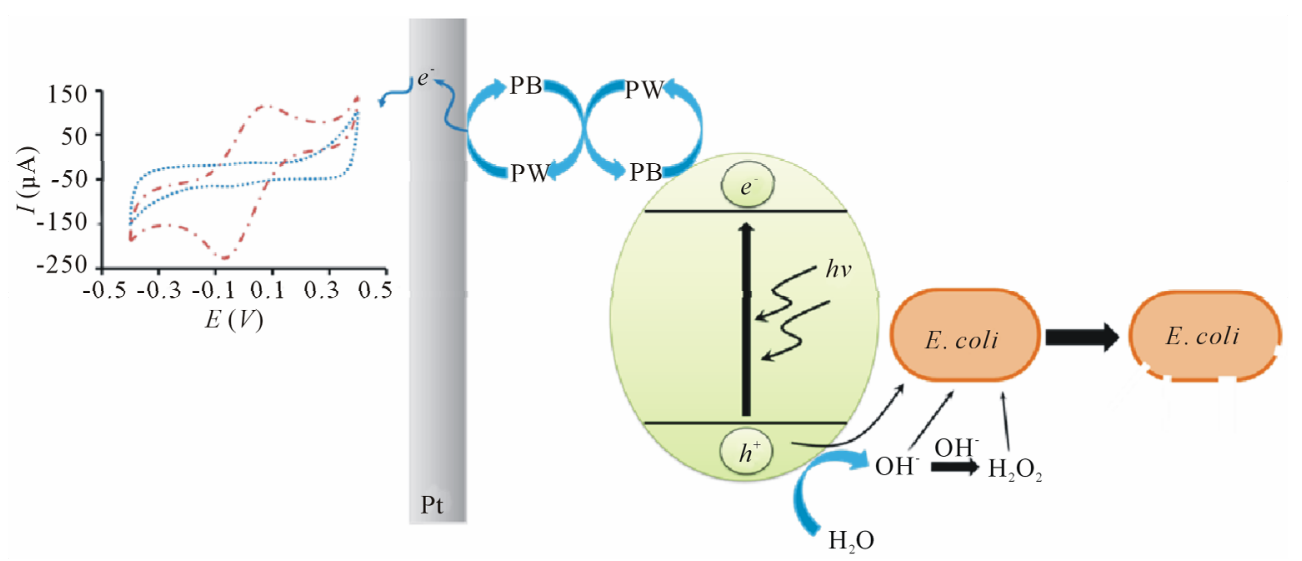

Scheme 2. Schematic diagram of principle of operation of bacterial sensor and photocatalytic inactivation of $E$. coli by $\mathrm{TiO}_{2}$ under UV light irradiation.

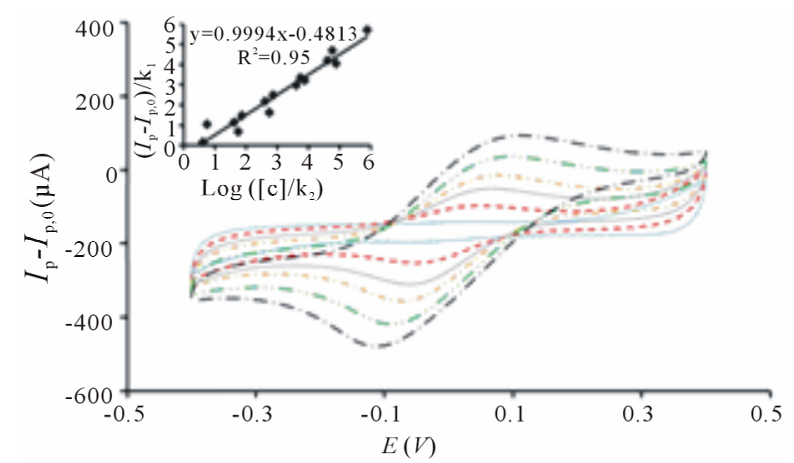

Figure 3. Cyclic voltammogram of $\mathrm{TiO}_{2}$ incorporated $\mathrm{PB}$ membrane sensor before irradiation $(\ldots . . . . .$.$) and after$ irradiation in the presence of $10 \mathrm{cfu} \cdot \mathrm{mL}^{-1}(---), 10^{2}$ cfu $\cdot \mathrm{mL}^{-1}\left(-\frac{1}{-}\right), 1^{3} \mathrm{cfu} \cdot \mathrm{mL}^{-1}(---), 10^{4} \mathrm{cfu} \cdot \mathrm{mL}^{-1}$ $(-\cdots), 10^{5} \mathrm{cfu} \cdot \mathrm{mL}^{-1}\left({ }^{-} \cdots\right)$. $I_{\mathrm{p}}$ represent the peak current signals in the presence of $E$. coli cells after $U V$ irradiation and $I_{p, 0}$ represents the peak current signal before irradiation. All potential sweeps were carried out in the presence of UV irradiation with increasing concentration of $E$. coli. Inset: Linear correlation between oxidative peak current with logarithm concentration of $E$. coli derived from three sets of experiments. Conditions: scan rate $=\mathbf{2 0}$ $\mathrm{mV} \cdot \mathrm{s}^{-1}$, potential range $=-0.4$ to $0.4 \mathrm{~V}$.

sor to acquire the next signal response. The difference in signal observed might be attributed to the mineralization of organic compounds by E. coli after prolonged mixing, contributing to slight increase in signal response [30]. This sensor shows its superior performance in E. coli detection even in the presence of organic contaminants, which are known to react with $\mathrm{TiO}_{2}[10,11]$, leading to its potential application in contaminated water analysis.

\subsection{Reproducibility and Regeneration of Bacterial Sensor}

The reproducibility of the fabrication procedure was determined by coating $\mathrm{PB}$ incorporated $\mathrm{TiO}_{2}$ onto platinum sputtered porous alumina membrane under identical con- ditions and measured the signal response toward 10 $\mathrm{cfu} \cdot \mathrm{mL}^{-1} E$. coli. The coefficient of variation of fabrication reproducibility for three different sensors was found to be within $8 \%$.

To investigate the reusability of the bacterial sensor, change of signal response before and after irradiation was monitored at $10 \mathrm{cfu} \cdot \mathrm{mL}^{-1} E$. coli in three independent experiments. After each analysis, the sensor was immersed in PBS for $10 \mathrm{~min}$ to ensure that bacteria cells had detached from the sensor prior to the next experiment. Single factor ANOVA test shows that there is no significant difference of the sensor signal response at 95\% confidence level. As shown in Figure 5, the sensors can be readily regenerated after rinsing with PBS solution and this presents an outstanding feature of the sensor since reusability has always been regarded as one of the most important features of bacterial biosensors for practical use [31].

\subsection{Applications of Bacterial Sensor}

To demonstrate useful applications of bacterial sensor for the analysis of total coliform in freshwater samples, analysis was conducted using untreated river water samples collected in clean sterile containers and subsequently spiked with $30 \mathrm{cfu} \cdot \mathrm{mL}^{-1} E$. coli. The E. coli concentration in the water sample was analyzed by comparing the $\mathrm{TiO}_{2}$ incorporated $\mathrm{PB}$ membrane sensor signal response to the standard calibration curve constructed in Figure 3. Real sample analysis of total coliform in river water samples shows excellent correlation of spiked concentrations and experimentally determined values at $95 \%$ confidence level. The sensor developed therefore can be applied for sensing and deactivation of bacteria in river water and it can also be widely used in the analysis of water samples from other sources.

Performance of the sensor was then evaluated on nonporous electrode, SPCE to compare with that of porous 


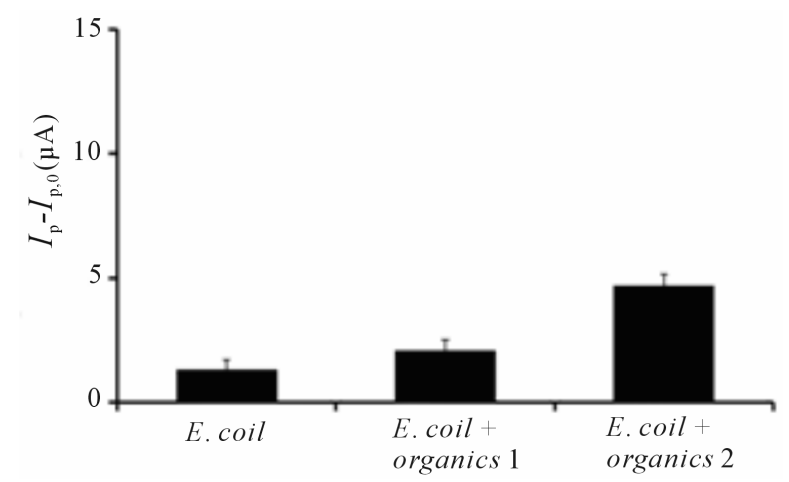

Figure 4. Change of oxidative peak current of $\mathrm{TiO}_{2}$ incorporated PB membrane sensor $\left(I_{p}-I_{p, 0}\right)$ toward $E$. coli, $E$. coli + organics 1 ( $E$. coli in a mixture of methanol, toluene and 1,4-dioxane) and $E$. coli + organics 2 ( $E$. coli incubated in a mixture of methanol, toluene and 1,4-dioxane for $1 \mathrm{~h}$ ). $I_{\mathrm{p}}$ represents the peak current signal in the presence of $E$. coli and $E$. coli in the mixture of organics upon irradiation while $I_{\mathrm{p}, 0}$ represents peak current signal before irradiation. Conditions: scan rate $=20 \mathrm{mV} \cdot \mathrm{s}^{-1}$, potential range $=-0.4$ to $0.4 \mathrm{~V}, \mathrm{E}$. coli concentration $=10 \mathrm{cfu} \cdot \mathrm{mL}^{-1}$, methanol concentration $=0.002 \mathrm{ppm}$, toluene concentration $=0.002 \mathrm{ppm}$, 1,4-dioxane concentration $=0.05 \mathrm{ppm}$.

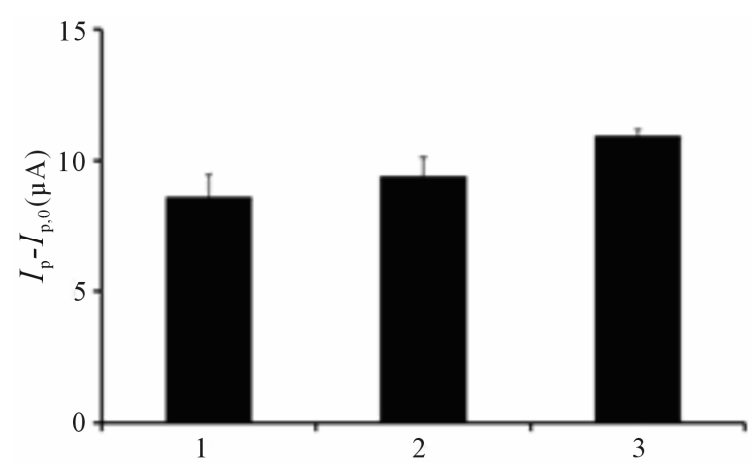

Figure 5. Change of oxidative peak current of $\mathrm{TiO}_{2}$ incorporated PB membrane sensor $\left(I_{p}-I_{p, 0}\right)$ toward $E$. coli for three different sets of experiments. $I_{p}$ represents signal response after $E$. coli was applied onto the sensor followed by irradiation while $I_{\mathrm{p}, 0}$ represents the signal response before irradiation. Conditions: scan rate $=20 \mathrm{mV} \cdot \mathrm{s}^{-1}$, potential range $=-0.4$ to $0.4 \mathrm{~V}, E$. coli concentration $=10 \mathrm{cfu} \cdot \mathrm{mL}^{-1}$.

alumina membrane electrode. Figure 6 gives the signal response of $\mathrm{PB}-\mathrm{TiO}_{2}$ coated SPCE with increasing concentration of E. coli. The correlation between logarithm concentration of $E$. coli and peak current follows Equation (1) and the linear range from 10 to $10^{5} \mathrm{cfu} \cdot \mathrm{mL}^{-1}$ is established. However, the current range obtained from PB-TiO ${ }_{2}$ coated SPCE is lower that than of $\mathrm{TiO}_{2}$ incorporated $\mathrm{PB}$ membrane sensor due to its non-porous structure and smaller surface area [32]. This suggests the highly regular, rigid and dense porous material with high pore density favors high PB loading and it can also act as reservoir of $\mathrm{PB}$ that restricts $\mathrm{PB}$ leaking, resulting in higher current range [33].

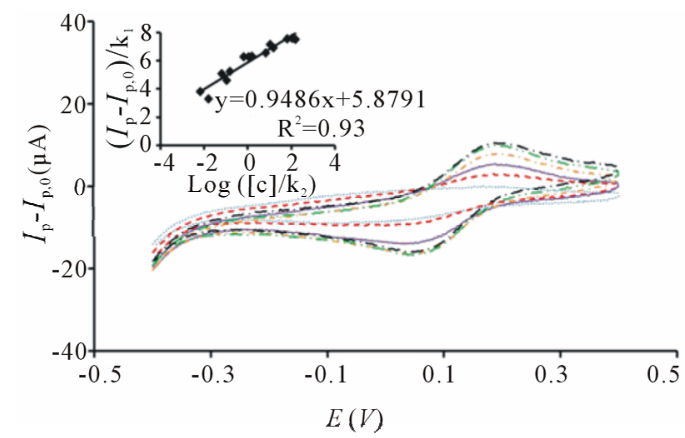

Figure 6. Cyclic voltammogram of $\mathrm{PB}^{-\mathrm{TiO}_{2}}$ coated SPCE before irradiation (.........) and after irradiation in the presence of $10 \mathrm{cfu} \cdot \mathrm{mL}^{-1}(---), 10^{2} \mathrm{cfu} \cdot \mathrm{mL}^{-1}(\square)$, $10^{3} \mathrm{cfu} \cdot \mathrm{mL}^{-1}(-\cdots), 10^{4} \mathrm{cfu} \cdot \mathrm{mL}^{-1}\left({ }^{-} \cdots\right), 10^{5} \mathrm{cfu} \cdot \mathrm{mL}^{-1}$ $(-\cdots) . I_{p}$ represent the peak current signals in the presence of $E$. coli cells after $U V$ irradiation and $I_{p, 0}$ represents the peak current signal before irradiation. All potential sweeps were carried out in the presence of UV irradiation with increasing concentration of $E$. coli. Inset: Linear correlation between oxidative peak current with logarithm concentration of $E$. coli derived from three sets of experiments. Conditions: $\operatorname{scan}$ rate $=20 \mathrm{mV} \cdot \mathrm{s}^{-1}$, potential range $=$ -0.4 to $0.4 \mathrm{~V}$.

\section{Conclusion}

In conclusion, we describe a unique bacterial sensor comprising PB coated porous membrane or SPCE electrode incorporated with $\mathrm{TiO}_{2}$ particles which demonstrate high sensitivity bacterial sensing utility and simultaneously, deactivate the bacteria. Unlike other detection methods which require lengthy incubation time, this sensor exhibits change of signal response immediately after the application of E. coli solution onto the sensor and at the start of detection procedure. The sensor also shows its specificity towards $E$. coli when tested against organic contaminants which are commonly present in industrial effluent and polluted groundwater and this feature is extremely useful in the monitoring of water quality which bacteria act as the contamination indicators. The simple integrated two electrode setup of $\mathrm{TiO}_{2}$ incorporated $\mathrm{PB}$ membrane sensor shows its superior analytical performance in detection of total coliform in water sample derived from river water. In addition, the higher current output of membrane sensor at low analyte concentrations as compared to $\mathrm{PB}-\mathrm{TiO}_{2}$ coated SPCE suggests its potential development into low cost and portable water disinfection system which can be highly applicable in developing countries where UV irradiation is readily available. Because of the potential ease of miniaturizing of the two electrode setup, this sensor could be developed into a powerful contamination monitoring tool for on-site analysis of water from various sources.

\section{Acknowledgements}

The authors thank NTU for research grant and J.S.H. 
acknowledges National Research Foundation (Environment and Water Technologies) for PhD scholarship.

\section{REFERENCES}

[1] P. R. Hunter, J. M. Colford, M. W. LeChevallier, S. Binder and P. S. Berger, "Waterborne Diseases," Emerging Infectious Disease, Vol. 7, No. 7, 2001, p. 544. http://dx.doi.org/10.3201/eid0707.017723

[2] T. F. Clasen and H. Laurence, "Water Quality Interventions to Prevent Diarrhoea," World Health Organization, Geneva, 2008.

[3] D. Battistel, F. Baldi, D. Marchetto, M. Gallo and S. Daniele, "A Rapid Electrochemical Procedure for the Detection of $\mathrm{Hg}(0)$ Produced by Mercuric-Reductase: Application for Monitoring Hg-Resistant Bacteria Activity," Environmental Science \& Technology, Vol. 46, No. 19, 2012, pp. 10675-10681. http://dx.doi.org/10.1021/es301444a

[4] E. Neumann, K. Tönsing and P. Siemens, "Perspectives for Microelectrode Arrays for Biosensing and Membrane Electroporation," Bioelectrochemistry, Vol. 51, No. 2, 2000, pp. $125-132$.

http://dx.doi.org/10.1016/S0302-4598(99)00084-7

[5] M. S. Cheng, S. H. Lau, V. T. Chow and C. S. Toh, "Membrane-Based Electrochemical Nanobiosensor for Escherichia coli Detection and Analysis of Cells Viability," Environmental Science \& Technology, Vol. 45, No. 15, 2011, pp. 6453-6459. http://dx.doi.org/10.1021/es200884a

[6] M. S. Cheng, J. S. Ho, C. H. Tan, J. P. S. Wong, L. C. Ng and C. S. Toh, "Development of an Electrochemical Membrane-Based Nanobiosensor for Ultrasensitive Detection of Dengue Virus," Analytica Chimica Acta, Vol. 725, 2012, pp. 74-80.

http://dx.doi.org/10.1016/j.aca.2012.03.017

[7] S. K. Yadav, P. Chandra, R. N. Goyal and Y.-B. Shim, "A Review on Determination of Steroids in Biological Samples Exploiting Nanobio-Electroanalytical Methods," Analytica Chimica Acta, Vol. 762, 2013, pp. 14-24. http://dx.doi.org/10.1016/j.aca.2012.11.037

[8] V. C. Diculescu, S. Kumbhat and A. M. Oliveira-Brett, "Electrochemical Behaviour of Isatin at a Glassy Carbon Electrode," Analytica Chimica Acta, Vol. 575, No. 2, 2006, pp. 190-197. http://dx.doi.org/10.1016/j.aca.2006.05.091

[9] C. M. A. Brett and A. M. Oliveira-Brett, "Electrochemical Sensing in Solution-Origins, Applications and Future Perspectives," Journal of Solid State Electrochemistry, Vol. 15, No. 7-8, 2011, pp. 1487-1494. http://dx.doi.org/10.1007/s10008-011-1447-z

[10] T. Matsunaga, R. Tomoda, T. Nakajima and H. Wake, "Photoelectrochemical Sterilization of Microbial Cells by Semiconductor Powders," FEMS Microbiology Letters, Vol. 29, No. 1-2, 1985, pp. 211-214. http://dx.doi.org/10.1111/j.1574-6968.1985.tb00864.x

[11] J.-M. Herrmann, "Heterogeneous Photocatalysis: Fundamentals and Applications to the Removal of Various Types of Aqueous Pollutants," Catalysis Today, Vol. 53, No. 1,
1999, pp. 115-129.

http://dx.doi.org/10.1016/S0920-5861(99)00107-8

[12] L. Sun and J. R. Bolton, "Determination of the Quantum Yield for the Photochemical Generation of Hydroxyl Radicals in $\mathrm{TiO}_{2}$ Suspensions," The Journal of Physical Chemistry, Vol. 100, No. 10, 1996, pp. 4127-4134. http://dx.doi.org/10.1021/jp9505800

[13] B. T. T. Nguyen, J. Q. Ang and C. S. Toh, "Sensitive Detection of Potassium Ion Using Prussian Blue Nanotube Sensor," Electrochemistry Communications, Vol. 11, No. 10, 2009, pp. 1861-1864. http://dx.doi.org/10.1016/j.elecom.2009.08.003

[14] M. C. Henstridge and R. G. Compton, "Mass Transport to Micro- and Nanoelectrodes and Their Arrays: A Review," The Chemical Record, Vol. 12, No. 1, 2012, pp. 63-71. http://dx.doi.org/10.1002/tcr.201100032

[15] N. Baram, D. Starosvetsky, J. Starosvetsky, M. Epshtein, R. Armon and Y. Ein-Eli, "Enhanced Inactivation of $E$. coli Bacteria Using Immobilized Porous $\mathrm{TiO}_{2}$ Photoelectrocatalysis," Electrochimica Acta, Vol. 54, No. 12, 2009, pp. 3381-3386. http://dx.doi.org/10.1016/j.electacta.2008.12.033

[16] M. Nishizawa, S. Kuwabata and H. Yoneyama, "Photoimage Formation in a $\mathrm{TiO}_{2}$ Particle-Incorporated Prussian Blue Film," Journal of the Electrochemical Society, Vol. 143, No. 11, 1996, pp. 3462-3465. http://dx.doi.org/10.1149/1.1837237

[17] W. Jin, Z. Chu and Y. Zhang, "Design and Preparation of Nanostructured Prussian Blue Modified Electrode for Glucose Detection,” In: P. A. Serra, Ed., New Perspectives in Biosensors Technology and Applications, InTech, 2011, pp. 329-342. http://dx.doi.org/10.5772/17798

[18] A. Goel, R. Bhatt and N. Rani, "Removal of Methyl Orange, an Azo Dye, Using Oxidative Degradation by Hexacyanoferrate(III) Ions," Discovery Science, Vol. 2, No. 4, 2012, pp. 32-36. discovery.org.in/ds/A201210_07

[19] H. Yu, J. Ma, Y. Zhang, X. Zhang and W. Shi, "Cyclic Voltammetry Studies of $\mathrm{TiO}_{2}$ Nanotube Arrays Electrode: Conductivity and Reactivity in the Presence of $\mathrm{H}^{+}$and Aqueous Redox Systems," Electrochimica Acta, Vol. 56, No. 18, 2011, pp. 6498-6502. http://dx.doi.org/10.1016/j.electacta.2011.05.004

[20] K. Sunada, T. Watanabe and K. Hashimoto, "Studies on Photokilling of Bacteria on $\mathrm{TiO}_{2}$ Thin Film," Journal of Photochemistry and Photobiology A: Chemistry, Vol. 156, No. 1, 2003, pp. 227-233.

http://dx.doi.org/10.1016/S1010-6030(02)00434-3

[21] P. C. Maness, S. Smolinski, D. M. Blake, Z. Huang, E. J. Wolfrum and W. A. Jacoby, "Bactericidal Activity of Photocatalytic $\mathrm{TiO}_{2}$ Reaction: Toward an Understanding of Its Killing Mechanism," Applied and Environmental Microbiology, Vol. 65, No. 9, 1999, pp. 4094-4098.

[22] K. Sunada, Y. Kikuchi, K. Hashimoto and A. Fujishima, "Bactericidal and Detoxification Effects of $\mathrm{TiO}_{2}$ Thin Film Photocatalysts," Environmental Science \& Technology, Vol. 32, No. 5, 1998, pp. 726-728. http://dx.doi.org/10.1021/es970860o

[23] Z.-X. Lu, L. Zhou, Z.-L. Zhang, W.-L. Shi, Z.-X. Xie, H.-Y. Xie, D.-W. Pang and P. Shen, "Cell Damage In- 
duced by Photocatalysis of $\mathrm{TiO}_{2}$ Thin Films," Langmuir, Vol. 19, No. 21, 2003, pp. 8765-8768.

http://dx.doi.org/10.1021/la034807r

[24] H. Foster, I. Ditta, S. Varghese and A. Steele, "Photocatalytic Disinfection Using Titanium Dioxide: Spectrum and Mechanism of Antimicrobial Activity," Applied Microbiology and Biotechnology, Vol. 90, No. 6, 2011, pp. 1847-1868. http://dx.doi.org/10.1007/s00253-011-3213-7

[25] W. Wang, Y. Yu, T. An, G. Li, H. Y. Yip, J. C. Yu and P. K. Wong, "Visible-Light-Driven Photocatalytic Inactivation of E. coli K-12 by Bismuth Vanadate Nanotubes: Bactericidal Performance and Mechanism," Environmental Science \& Technology, Vol. 46, No. 8, 2012, pp. 45994606. http://dx.doi.org/10.1021/es2042977

[26] A. Rompre, P. Servais, J. Baudart, M.-R. de-Roubin and P. Laurent, "Detection and Enumeration of Coliforms in Drinking Water: Current Methods and Emerging Approaches," Journal of Microbiological Methods, Vol. 49, No. 1, 2002, pp. 31-54. http://dx.doi.org/10.1016/S0167-7012(01)00351-7

[27] H. M. Coleman, V. Vimonses, G. Leslie and R. Amal, "Degradation of 1,4-Dioxane in Water Using $\mathrm{TiO}_{2}$ Based Photocatalytic and $\mathrm{H}_{2} \mathrm{O}_{2}$ /UV Processes," Journal of Hazardous Materials, Vol. 146, No. 3, 2007, pp. 496-501. http://dx.doi.org/10.1016/j.jhazmat.2007.04.049

[28] World Health Organization, "Guidelines for DrinkingWater Quality,” Geneva, 2011.
[29] N. D. Bedding, A. E. McIntyre, R. Perry and J. N. Lester, "Organic Contaminants in the Aquatic Environment I. Sources and Occurrence," Science of the Total Environment, Vol. 25, No. 2, 1982, pp. 143-167. http://dx.doi.org/10.1016/0048-9697(82)90083-3

[30] E. Diaz, A. Ferrandez, M. A. Prieto and J. L. Garcia, "Biodegradation of Aromatic Compounds by Escherichia coli," Microbiology and Molecular Biology Reviews, Vol. 65, No. 4, 2001, pp. 523-569. http://dx.doi.org/10.1128/MMBR.65.4.523-569.2001

[31] K. Yagi, "Applications of Whole-Cell Bacterial Sensors in Biotechnology and Environmental Science," Applied Microbiology and Biotechnology, Vol. 73, No. 6, 2007, pp. 1251-1258.

http://dx.doi.org/10.1007/s00253-006-0718-6

[32] J. H. Yuan, K. Wang and X. H. Xia, "Highly Ordered Platinum-Nanotubule Arrays for Amperometric Glucose Sensing," Advanced Functional Materials, Vol. 15, No. 5, 2005, pp. 803-809. http://dx.doi.org/10.1002/adfm.200400321

[33] A. Curulli, F. Valentini, S. Orlanduci, M. L. Terranova and G. Palleschi, "Pt Based Enzyme Electrode Probes Assembled with Prussian Blue and Conducting Polymer Nanostructures," Biosensors and Bioelectronics, Vol. 20, No. 6, 2004, pp. 1223-1232. http://dx.doi.org/10.1016/j.bios.2004.06.026 